\title{
The Internet Public Library (IPL): An Exploratory Case Study on User Perceptions
}

Monica Maceli, Susan Wiedenbeck,
and Eileen Abels

The Internet Public Library (IPL), now known as ipl2, was created in 1995 with the mission of serving the public by providing librarian-recommended Internet resources and reference help. We present an exploratory case study on public perceptions of an "Internet public library," based on qualitative analysis of interviews with ten college student participants: some current users and others unfamiliar with the IPL. The exploratory interviews revealed some confusion around the IPL's name and the types of resources and services that would be offered. Participants made many positive comments about the IPL's resource quality, credibility, and personal help.

$\mathrm{T}$ he Internet Public Library (IPL), now known as ipl2, is an online-based public service organization and a learning and teaching environment originally developed by the University of Michigan's School of Information and currently hosted by Drexel University's iSchool. The IPL was created in 1995 as a project in a graduate seminar; a diverse group of students worked to create an online space that would be both a library and an Internet institution, helping librarians and the public identify useful Internet resources and content collections. With a strong mission to serve and educate a varied community of users, the IPL sought to help the public navigate the increasingly complex Internet environment as well as advocate for the continuing relevance of librarians in a digital world. The resulting IPL provided online reference, content collections (such as ready reference and a full-text reading room), youth-oriented resources, and services for other librarians, all through its free, web-based presence. ${ }^{1}$ Currently, the IPL consists of a publicly accessible website with several large content collections (such as "POTUS: Presidents of the United States"), sections targeted toward teens and children ("TeenSpace" and "KidSpace"), and a question and answer service where users can e-mail questions to be answered by volunteer librarians. ${ }^{2}$

There has been an enormous amount of change in the Internet and digital libraries since the IPL's inception in 1995. While web use statistics, user feedback, and incoming patron questions indicate that the IPL remains well-used and valued, there are many questions about its place in an increasingly information-rich online

Monica Maceli (mgm36@drexel.edu) is a Doctoral Student, Susan Wiedenbeck (susan.wiedenbeck@drexel.edu) is a Professor, and Eileen Abels (eabels@drexel.edu) is a Professor at the College of Information Science and Technology, Drexel University, Philadelphia. environment. Digital and physical holdings, academic and public libraries, free and subscription resources, Internet encyclopedias, and a multitude of other offerings form a complex (and often overwhelming) informationseeking environment. To move forward effectively and to best serve its existing and potential users, the IPL must pursue a path that is adapted to the present state of the Internet and that is user-informed and user-driven.

Recent large-scale studies, such as the 2005 OCLC reports on perceptions of libraries and information resources, have begun to explore user perceptions of libraries in the complex Internet environment. ${ }^{3}$ These studies emphasize the importance of user perceptions of library use, questioning whether libraries still matter in the rapidly growing infosphere and what future use trends might be. In the Internet environment, user perceptions play a key role in use (or nonuse) of library resource and services as information-seekers are faced with myriad easily accessible electronic information sources. The IPL's name, for example, may or may not be perceived as initially helpful to users' information-seeking needs. Repeat use relates to such perceptions as well, in the amount of value users perceive in the library resources over the many other sources available. In beginning to explore such issues, there is a need for current research addressing user perceptions of an Internet public library: what the name implies to both existing and potential users as well as the associated functions and resources that should be offered.

In this study, we present an exploratory case study on public perceptions of the IPL. Using qualitative analysis of interviews with ten college students, some of whom are current users of the IPL and others with no exposure to the IPL, begins to yield an understanding of the public perception of what an Internet public library should be. This study seeks to expand our understanding of such issues and explore the present-day requirements for the IPL in addressing the following research questions:

- What is the public perception of an Internet public library?

- What services and materials should an Internet public library offer?

\section{Background}

\section{The IPL: Origins and Research}

In 1995, Joe Janes, a professor at the University of Michigan's School of Information and Library Studies, ran a graduate seminar in which a group of students created a web-based library intended to be a hybrid of both physical library services and Internet resources and offerings. The resulting IPL would take the best from both the physical and digital 
worlds while developing its own unique offerings and features. ${ }^{4}$ Janes had conceived the idea in 1994, when the Internet's continued growth began to make it clear that the role of libraries and librarians would be forever changed as a result. Janes' motivating question was "what does librarianship have to say to the network environment and vice versa?" ${ }^{5}$ The IPL tackled a broad mission of enhancing the value of the Internet by providing resources to its varied users, educating and strengthening that community, and (perhaps most unique at the time) communicating "its' creators vision of the unique roles of library culture and traditions on the Internet." ${ }^{6}$ Initial student brainstorming sessions yielded the priorities that the IPL would address and included such services as reference, community outreach, and youth services.

The first version of the IPL contained electronic versions of classic library offerings, such as magazines, texts, serials, newspapers, and an e-mail reference service. The IPL was well received and continued its development, adding and expanding resources to support specific communities such as teens and children. The IPL was awarded several grants over the next few years, allowing for expansion and continuation. ${ }^{7}$ A wealth of librarian volunteers, composed of students and staff, contributed to the IPL, in particular toward the e-mail reference services. With a stated goal of responding to patrons' questions within one week, the reference services provide help and direct contact with the IPL's user base, many of whom are students working on school assignments. ${ }^{8}$ The IPL's collections are discoverable through search engines (popular offerings such as the "POTUS: Presidents of the United States" resources rank highly in search results lists) and through its presence on social networking sites such as Myspace, Facebook, and Twitter. Additionally, IPL distributes brochures to teachers and librarians at relevant conferences.

The IPL has been the focus of many research studies covering a broad range of themes, such as its history and funding, digital reference and the IPL's question-andanswer service, and its resources and collections. ${ }^{9}$ Also, in line with the original mission of the IPL, Janes developed The Internet Public Library Handbook to share best practices with other librarians. ${ }^{10}$ The majority of publications, however, have focused on IPL's reference service, which is uniquely placed as a librarian-staffed volunteer digital reference service. As the IPL has collected and retained all reference interactions since its inception in 1995, there is a wealth of data readily available to such studies and exploratory work into how best to analyze it. ${ }^{11}$

\section{User Perceptions of Digital Libraries}

The Internet is a vastly different world than it was in the early days of the IPL's creation. The expectations of library patrons, both in digital and in physical environments, have changed as well. And as the Internet evolves there has also been a continuous evaluation of the role of the library in an increasingly digital world, a question Janes sought to address in his first imaginings of the IPL. A study conducted in 2005 claimed that "electronic information-seeking by the public, both adults and children, is now an everyday reality and large numbers of people have the expectation that they should be able to seek information solely in a virtual mode if they so choose."12 This trend in electronic information-seeking has driven both public and academic libraries to create and support vast networks of licensed and free online information, directories, and guides. These electronic offerings, which (at least in theory) are desired and appreciated by users, are often overshadowed by the wealth of quickly accessible information from tools such as search engines. ${ }^{13}$ In competition with quickly accessible (though not necessarily credible or accurate) information sources, librarians have struggled to find their place and relevance in an evolving environment. Google and other web search engines often shape users' experiences and expectations with information-seeking, more so than any formal librarian-driven instruction such as in Boolean searching.

Several recent comprehensive studies have explored user perceptions of libraries, both physical and digital, in relationship to the larger Internet. Abels explored the perspective of libraries and librarians across a broad population consisting of both library users and non-users. ${ }^{14} \mathrm{Her}$ findings included the fact that web search engines were the starting point for the majority of information-seeking, and that there is a high preference among users for virtual reference desk services. She proposed an information-seeking model in which the library serves as one of many Internet resources, including free websites and interpersonal sources, and is likely not the user's first stop. In respect to this model of information-seeking, Abels suggests that "librarians need to accept the broader framework of the information seeker and develop services that integrate the library and the librarian into this framework."15

In 2005, OCLC released what is possibly the most comprehensive study to date of the public's perceptions of library and information resources as explored on a number of levels, including both the physical and digital environments. ${ }^{16}$ Findings relevant to libraries on the Internet (and this study) included the following:

- 84 percent of participants reported beginning an information search from a search engine; only 1 percent started from a library website

- there was a preference for self-service and a tendency to not seek assistance from library staff

- users were not aware of most libraries' electronic resources

- college students have the highest rate of library use

- users typically cross-reference other sites to validate their results 
A portion of the study focused on library identity or brand in the mind of the public; participants found the library brand to be "books," with no other terms or concepts coming close. As a companion report to this study, OCLC released a report focused on the library perceptions of college students. ${ }^{17}$ As our study uses a college student participant base, OCLC's findings are highly relevant. The vast majority of college students reported using search engines as a starting point for informationseeking and expressed a strong desire for self-service library resources. As compared to the general population, however, college students have the highest rate and broadest use of both physical and digital library resources and a corresponding high awareness of these services.

The relationship between public libraries and the Internet was explored in depth in a 2002 study by $\mathrm{D}^{\prime}$ Elia et al. ${ }^{18}$ The study sought to systematically investigate patrons' use of the Internet and of public libraries. Findings included the fact that the Internet and public libraries are often complementary; that more than half of Internet users were library users and vice versa; and that libraries are valued more than the Internet for providing accurate information, privacy, and child-oriented spaces and services. Participants made a distinction between the service characteristics of the public library versus those of the Internet. Many of the most-valued characteristics of the Internet (such as information that is always available when needed) were not supported by physical libraries because of limited offerings and hours.

In addition to large, comprehensive surveys, there have been several case-study approaches, exploring user perceptions of a particular digital library or library feature. Tammaro researched user perceptions of an Italian digital library, finding the catalog, online databases, and electronic journals to be most valued; she found speed of access, remote access, a larger number of resources, and personalization to be key digital library services. ${ }^{19}$ This study also reported a consistent theme in digital library literature: a patron base primarily consisting of novice users who do not know how to use the library and are unaware of the various services offered. Crowley et al. evaluated an existing academic library's webpages for issues and user needs. ${ }^{20}$ They identified issues with navigational structures and overly technical terminology and a general need for robust help and extensive research portals.

In respect to our study, we found no literature that studied perceptions of Internet public libraries. As mentioned earlier, research that addressed the IPL from the perspective of its patrons largely focused on IPL's reference services. In 2008, IPL staff reported 13,857 reference questions received and 9,794,292 website visitors. ${ }^{21}$ Although reference is clearly a vital and well-used service, there is also a great deal of website collection use that must be researched. Recent literature does not address the current state of the IPL from the perspective of the public, which is the intention of this study.

\section{Method}

This exploratory study consisted of a qualitative analysis of data gathered from interviews and observations of ten college student participants who were academic library users and nonusers of the IPL. A pilot study preceded the final research effort and allowed us to iteratively tailor the study design to best pursue our research questions. Our initial study design incorporated a usability test portion, in which users were presented with a series of information-seeking needs and instructed to use the IPL's website to answer the questions. However, we later dropped this portion of the study because pilot results found that it contributed little to answering our research questions about public perceptions; it largely explored implementation details, which was not the focus of this study.

Following the pilot study, we recruited ten Drexel University students from the university's W. W. Hagerty Library. This ensured recruiting participants who were at least minimally familiar with physical libraries and who were from a variety of academic focuses. The participant group included eight females and two males-two were graduate students, eight were undergraduates-from a variety of majors, including biology, biomedical engineering, business, library science, accounting, international studies, and information systems. Participants took an average of twenty-six minutes to complete the study.

The study consisted of a short interview to assess the user's experience with public libraries (both physical and online) and their expectations of an Internet public library. These open-ended questions (included in the appendix) sought to determine what features, services, or content were desired or expected by users, whether the term of "Internet public library" was meaningful, if there were similarities to web-based systems that the participants were already familiar with, or if they had previously used a website they would consider an Internet public library. All interviews were audio recorded and transcribed. An initial coding scheme was established and iteratively developed (table 1).

Once we observed significant overlap between participant responses, the study then proceeded to the final analysis and presentation, using inductive qualitative analysis to code text and identify themes from the data. ${ }^{22}$

\section{Findings}

All participants were current or former public library patrons; six participants (P1, P4, P5, P6, P8, and P9) were 
Table 1. Inductive Coding Scheme Developed from Raw Transcript Text, Used to Identify Key Themes

\begin{tabular}{l}
\hline Coding Scheme \\
Physical public libraries \\
Tied to life phase \\
Confusion between academic and public \\
Current use \\
Frequency of use \\
Perceptions of an Internet public library \\
Access \\
Properties of physical libraries \\
Reference \\
Resources \\
Tools \\
Users \\
General Internet use \\
Academic library use \\
Similar sites to IPL
\end{tabular}

current public library users, and four (P2, P3, P7, and P10) had used public libraries in the past but were no longer using their services. Two participants were graduate students (P3 and P9) with the remainder undergraduates, and two of the ten students had used the IPL website before (P3 and P6). The participants could be characterized as relatively infrequent public library users with a strong interest in the physical book holdings of the public library, primarily for leisure but frequently for research as well. Several participants mentioned scholarly databases that were provided by their public library (typically from within the library or online with access using a public library card). There was also interest in leisure audiovisual offerings and in using the library as a destination for leisure.

The following themes illustrate our main findings with respect to our research questions. As described above, we conceptualized our raw data into broad themes through an iterative process of inductive coding and analysis. Although multiple themes emerged as associated with each of our research questions, we present only the most important and relevant themes (see table 2). All themes were supported by responses from multiple participants. We will further elaborate the themes discovered later in this section; a selected relevant and meaningful participant quote illustrates each theme.

\section{Theme 1: Confusion about Name}

"Internet public library" was not an immediately clear term to four of the participants; the six other participants were able to immediately begin describing their concept of such a library. A few remained confused about how such a concept would relate to physical public libraries and the Internet in general. One participant assumed that such a term must mean the web presence of a particular physical public library. Another's immediate reaction was to question the value of such a venture in light of existing Internet resources: "I mean, the Internet is already useful, so I don't know [how useful it would be]" (P2).

Two other participants found meaning in the term by associating it with a known library website, such as that of their academic library or local physical public library.

When asked what websites seem similar in function or appearance to what they would consider an Internet public library, responses varied. While most participants could not name any similar website or service, one mentioned several academic library websites that he was familiar with, another described several bookseller websites (Amazon.com, Half.com, and AbeBooks.com), and a third mentioned Wikipedia (but then immediately retracted the statement, after deciding that Wikipedia was not a library).

\section{Theme 2: Quick and Easy, but Still Credible}

Participants were highly enthusiastic about the perceived benefits in access to and credibility of information from an Internet public library. Ease of use and faster information access, often from home, were key motivators for use of Internet-based libraries, both public and academic. As described earlier, there is a wealth of competing information options freely available on the Internet. Given this, participants felt that an Internet public library would offer the most value because of its credible information:

\begin{abstract}
I like the ready reference [almanacs, encyclopedias]. ... I'm not used to using any of these, Wikipedia is just so ready and user friendly. It's so easy to go to Wikipedia but it's not necessarily credible. . . Whereas I feel like this is definitely credible. It's something I could use if I needed to in some sort of academic setting. (P10)
\end{abstract}

\section{Theme 3: Lack of Differentiation between Public and Academic; Physical and Digital Libraries}

For many participants, there was confusion about what was or was not a public library, and they initially considered their academic library in that category. Overall, participants did not think of public and academic libraries (physical or on the Internet) as distinctly different; rather they were more likely to be associated with phase of life. Participants that were not current public library users reported using public libraries frequently during their years of elementary education. For participants that were current public library users, physical public libraries (and other local academic libraries) were used to fill in the gaps 
Table 2. Themes Identified

\begin{tabular}{ll}
\hline Research Question & Themes Identified \\
\hline $\begin{array}{ll}\text { What is the public perception of } \\
\text { an Internet public library? }\end{array}$ & Confusion about name \\
& Quick and easy, but still credible \\
& Lack of differentiation between public and academic; physical and digital libraries \\
\hline What services and materials & Electronic resources, catalog, and searching tools are key \\
would such a website offer? & Connections to physical libraries \\
& Personal and personalized help \\
\hline
\end{tabular}

for items that could not be located at their school's academic library, either through physical or digital offerings.

Consistent with this finding, a few participants reported conducting searches across both local academic and public libraries in pursuit of a particular item. There was a general disregard for where the item came from, as long as it could be acquired with relatively little effort from physically close local or online resources. However, participants reported typically starting with their academic libraries for school resources and the public libraries for leisure materials "I go to the Philadelphia public library probably once a month or so usually for DVDs but sometimes for books that I can't find here [academic library]. . . . I usually check here first because it's closer." (P5)

\section{Theme 4: Electronic Resources, Catalog, and Searching Tools are Key}

There were many participant comments, and some confusion, around what type of resources an Internet public library would provide, as well as whether they would be free or not (one participant assumed there would be a fee to read online). The desired resources (in order of importance) included leisure and research e-books, scholarly databases, online magazines and newspapers, and DVDs and CDs (pointers to where those physical items could be found in local libraries). A few comments were negative, assuming the resources provided would only be electronic, but participants were mostly enthusiastic about the types and breadth of resources that such a website would offer. For example, one participant commented, "I think you could get more resources. ... The library I usually visit is kind of small so it's very limited in the range of information you can find." (P4)

Many participants emphasized the importance of providing robust, yet easy-to-use, search tools in managing complex information spaces and conveying item availability.

\section{Theme 5: Connections to Physical Libraries}

Several participants assumed that the resource collection would contain both electronic online items and locally available items in physical formats. In particular, connections to local physical libraries to share item holdings and availability status were desired: "General book information and maybe a list of where books can be found. Like online, the local place you can find the books." (P7)

Given that information-seeking, for this group, was conducted indiscriminately across physical and digital libraries, this integrated view into local physical resources seems to be a natural request.

\section{Theme 6: Personal and Personalized Help}

Although no participants claimed that reference was a service that they typically use during their physical public library experiences, it was a strong expectation for an Internet public library and mentioned by nearly every participant. When questioned as to how this reference interaction should take place, there was a clear preference for communicating via instant message: "Reference information. ... You know, where you have real people. A place where you can ask questions.... If you think you can get an answer at a library, then online you would hope to get the same things." (P1)

In addition to being able to interact with a "real" librarian, participants desired other personalized elements, such as resources and services dedicated to information needy populations (like children) as well as resources supporting the community and personal lifestyle issues and topics (like health and money).

\section{Discussion}

In summary, we characterized the participants in this case study as low-frequency physical public library users with a high association between life phase (high school or grade school) and public library use. Participants looked to public libraries to provide physical books-primarily for leisure but often for research use as well-leisure DVDs and CDs, scholarly databases, and a space to "hang 
out" or occupy leisure time. For the participants, an Internet public library (an occasionally confusing term) described a service you could access from home, which included electronic books, information about locally available physical books, scholarly databases, reference or help services, and robust search tools. It must be easy to use and tailored to needy community populations such as children and teens. For several participants it would be similar to existing bookseller websites (such as Amazon. com or AbeBooks.com) or academic library websites.

In exploring how these findings can inform the future design and direction of the IPL, it is again necessary to reflect on the values and concepts that inspired the original creation of the IPL. The initial choice of the IPL's name was intended to reflect a novel system at the time, as Joe Janes detailed in the IPL prospectus: "I would view each of those three words as equally important in conveying the intent of this project: Internet, Public, and Library. I think the combination of the three of them produces something quite different than any pair or individual might suggest."23

All three of these concepts-Internet, public, and library-have evolved with the changing nature of the Internet. And, as the research explored would indicate, there may not be a distinct boundary between these concepts from the perspective of users. Our finding that participants seek information by indiscriminately crossing public and academic libraries, as well as digital and physical resource formats verifies earlier research efforts. ${ }^{24}$ As the amount of information accessible on the Internet has expanded, the boundary of the library can be seen as either expanding (providing credible indexing, pointers, and information about useful resources from all over the Internet), contracting (primarily providing access to select resources that must be accessed through subscription), or existing somewhere in between, depending on the perspective.

In any of these cases, it is vital that the IPL present its resources, services, and offerings such that its value and contribution to information-seeking is highlighted and clear to users. Amorphously placed in a complex world of digital and physical information, the IPL must work toward creating a strong image of its offering and mission; an image that is transparent to its users, starting with its name. This challenge is not the IPL's alone, but rather that of all Internet library portals, resources, and services. The 2005 OCLC report on perceptions of libraries expressed the importance of a strengthened image for Internet libraries:

Libraries will continue to share an expanding infosphere with an increasing number of content producers, providers and consumers. Information consumers will continue to self-serve from a growing information smorgasbord. The challenge for libraries is to clearly define and market their relevant place in that infosphere-their services and collections both physical and virtual. ${ }^{25}$

This is, like many issues in library systems design, a complex challenge. As previous research has shown, extending the metaphor of the physical library into the digital environment does not always assist users, especially when they may be more likely to draw on previous experiences with other Internet resources. ${ }^{26}$ The original prospectus for the Internet Public Library, as developed by Joe Janes, acknowledges the different capabilities of physical libraries and libraries on the Internet, claiming that the IPL would "be a true hybrid, taking the best from both worlds but also evolving its own features." ${ }^{27}$ If users anticipate an experience similar to the Internet resources they typically use (such as search engines), then the IPL may best serve its users by moving closer to "Internet" than "library." However, such a choice may entail unforeseen tradeoffs. Several participants in this study mused over what physical public library characteristics would carry over to a digital public library and the potential tradeoffs: "You wouldn't have to leave your home but at the same time I think it's easier to wander the library and just see things that catch your eye. And I like the quiet setting of the library too." (P8)

Another participant mentioned the distinctly positive public library experience, and how such an experience should be reflected in an Internet-based public library: "I think that public libraries have a very positive reputation within communities. And I don't think it would be bad for an Internet public library to move toward that expectation that people have." (P3)

The question remains, then, whether the IPL can compete with a multitude of other Internet resources without losing the familiar and positive essence of a traditional physical public library. Or rather, how can the IPL find a way to translate that essence to a digital environment without sacrificing performance and user expectations of Internet services?

\section{Conclusion}

During this study, participants described an Internet public library that, in many ways, takes the best features of several currently existing and popular websites. An Internet public library should contain all the information of Wikipedia, yet be as credible as information received directly from your local librarian. It should search across both websites and physical holdings, like AbeBooks.com or a search aggregator. It should search as powerfully and as easily as Google, yet return fewer, more targeted results. And it should provide real-time help immediately and conveniently, all from the comfort of your home. 
These are clearly complex, far-reaching, and labor-intensive requirements. And many of these requirements are currently difficult and unresolved challenges to digital libraries in general, not simply the IPL.

This preliminary study is limited in its college student participant base and small sample size, which may not reflect perspectives of the greater community of IPL users. These results therefore may not be generalizable to other populations who are current or potential users of the IPL, including other targeted groups such as children and teens. Additionally, our chosen participant group, college students who are physical library users, had relatively high levels of library and technology experience, as well as complex expectations. Our results would likely differ with a participant group of novice Internet users.

As detailed above, this study explores public perceptions of an Internet public library-an important aspect of the IPL that is not well studied and that has implications on IPL use and repeat use. While the IPL was carefully and thoughtfully constructed by a dedicated group of librarians, students, and educators, there has not been a recent study devoted to understanding what an Internet public library should be today. More recently, in January 2010, the IPL merged with the Librarians' Internet Index to form ipl2. The two collections were merged and the website was redesigned. Although this merger was because of circumstances unrelated to our research, our findings were leveraged during the redesign (for example, in naming the collections). In the future, our findings can be used in further ip12 design iterations or explored in subsequent research studies in the specific context of ipl2 or of digital libraries in general. As discussed above, this study may be extended to different participant populations and to existing but remote ipl2 users. This study may also be continued in a more design-oriented direction to explore the usability and user acceptance of ipl2's website.

\section{References}

1. Joseph Janes, "The Internet Public Library: An Intellectual History," Library Hi Tech 16, no. 2 (1998): 55-68.

2. "About the Internet Public Library," Internet Public Library, http://ipl.org/div/about/ (accessed Feb. 17, 2009).

3. Cathy De Rosa et al., "Perceptions of Libraries and Information Resources," OCLC Online Computer Library Center, 2005, http://www.oclc.org/reports/pdfs/Percept_all .pdf (accessed Mar. 9, 2009); Cathy De Rosa et al., "College Students' Perceptions of Libraries and Information Resources," OCLC Online Computer Library Center, 2005, http://www .oclc.org/reports/pdfs/studentperceptions.pdf (accessed Mar. 9, 2009).

4. Janes, "The Internet Public Library," 55.

5. Ibid., 56 .

6. Ibid., 57.

7. Lorrie LeJeune, "Before Its Time: The Internet Public
Library," Journal of Electronic Publishing 3, no. 2 (1997).

8. David S. Carter and Joseph Janes, "Unobtrusive Data Analysis of Digital Reference Questions and Service at the Internet Public Library: An Exploratory Study," Library Trends 49 , no. 2 (2000): 251-65.

9. On the IPL's history and funding, see Barbara Hegenbart, "The Economics of the Internet Public Library," Library Hi Tech 16, no. 2 (1998): 69-83; Joseph Janes, "Serving the Internet Public: The Internet Public Library," Electronic Library 14, no. 2 (1996): 122-26; and Carter and Janes, "Unobtrusive Data Analysis," 251-65. On digital reference and IPL's question-andanswer service, see Kenneth R. Irwin, "Professional Reference Service at the Internet Public Library With 'Freebie' Librarians," Searcher-The Magazine for Database Professionals 6, no. 9 (1998): 21-23; Nettie Lagace and Michael McClennen, "Questions and Quirks: Managing an Internet-Based Distributed Reference Service," Computers in Libraries 18, no. 2 (1998): 24-27; Sara Ryan, "Reference Service for the Internet Community: A Case Study of the Internet Public Library Reference Division," Library $\mathcal{E}$ Information Science Research 18, no. 3 (1996): 241-59; and Elizabeth Shaw, "Real Time Reference in a Moo: Promise and Problems," Internet Public Library, http://www.ipl.org/div/iplhist/moo .html (accessed Dec. 4, 2008). On the IPL's resources and collections, see Thomas Pack, "A Guided Tour of the Internet Public Library-Cyberspace's Unofficial Library Offers Outstanding Collections of Internet Resources," Database 19, no. 5 (1996): $52-56$.

10. Joseph Janes, The Internet Public Library Handbook (New York: Neal Schuman, 1999).

11. Carter and Janes, "Unobtrusive Data Analysis," 251-65.

12. Gloria J. Leckie and Lisa M. Given, "Understanding Information-Seeking: The Public Library Context," Advances in Librarianship 29 (2005): 1-72.

13. James Rettig, "Reference Service: From Certainty to Uncertainty," Advances in Librarianship 30 (2006): 105-43.

14. Eileen Abels, "Information Seekers' Perspectives of Libraries and Librarians," Advances in Librarianship 28 (2004): 151-70.

15. Ibid., 168 .

16. Cathy De Rosa et al., "Perceptions of Libraries."

17. Cathy De Rosa et al., "College Students' Perceptions of Libraries."

18. George D'Elia et al., "The Impact of the Internet on Public Library Use: An Analysis of the Current Consumer Market for Library and Internet Services," Journal of the American Society for Information Science \& Technology 53, no. 10 (2002): 802-20.

19. Anna Maria Tammaro, "User Perceptions of Digital Libraries: A Case Study in Italy," Performance Measurement $\mathcal{E}$ Metrics 9, no. 2 (2008): 130-37.

20. Gwyneth H. Crowley et al., "User Perceptions of the Library's Web Pages: A Focus Group Study at Texas A\&M University," The Journal of Academic Librarianship 28, no. 4 (2002): 205-10.

21. Adam Feldman, e-mail to author, Apr. 3, 2009; Mark Galloway, e-mail to author, Apr. 3, 2009.

22. For information on inductive qualitative analysis, see David R. Thomas. "A General Inductive Approach for Analyzing Qualitative Evaluation Data" American Journal of Evaluation 27, no. 2 (2006): 237-46; Michael Quinn Patton, Qualitative Research and Evaluation Methods (Thousand Oaks, Calif.: Sage, 2002); 
and Matthew B. Miles and Michael Huberman, Qualitative Data Analysis: An Expanded Sourcebook, 2nd ed. (Thousand Oaks, Calif.: Sage, 1994).

23. Janes, "The Internet Public Library," 56.

24. For example, Stephann Makri et al., "A Library or Just Another Information Resource? A Case Study of Users' Mental Models of Traditional and Digital Libraries," Journal of the
American Society for Information Science \& Technology 58, no. 3 (2007): 433-45.

25. De Rosa et al., "College Students' Perceptions of Libraries," 146.

26. Makri et al., "A Library or Just Another Information Resource?" 434.

27. Joseph Janes, "The Internet Public Library," 56.

\section{Appendix. Interview Protocol}

- Have you ever visited a public library?

- If so, how often do you visit and why?

- What services do you typically use?

- Can you describe your last visit and what you were looking for?

- What do you think an Internet public library would be?

- What sort of services would it offer?

- What else should it do?

- Have you ever visited an Internet public library? 